\title{
Coriolis effects on wind jets and cloudiness along coasts
}

\section{Andrew Orr ${ }^{1}$ \\ Julian Hunt ${ }^{1}$ \\ Rachel Capon ${ }^{2}$ \\ Joel Sommeria $^{3}$ \\ Doug Cresswell ${ }^{1}$ \\ Antony Owinoh ${ }^{4}$}

\author{
${ }^{1}$ Centre for Polar Observation \& \\ Modelling, Dept. of Space \& Climate \\ Physics, University College London, \\ London, UK \\ ${ }^{2}$ Met Office Joint Centre for Mesoscale \\ Meteorology, University of Reading, \\ Reading, UK \\ ${ }^{3}$ Laboratoire Des Ecoulements \\ Geophysiques et Industriels/Coriolis, \\ Grenoble, France \\ ${ }^{4}$ Potsdam Institute for Climate Impact \\ Research, Potsdam, Germany
}

Coastal meteorology is complex and of great practical importance. The UK has the world's 14th longest coastline of over $12000 \mathrm{~km}$, with much of its population and many of its large cities situated along it. Many wind turbine 'farms' are being installed in coastal waters (e.g. at Blyth, Northumberland). Together with the expanded use of photo-voltaic systems and wave/tidal energy, it is intended to generate up to $20 \%$ of the UK's electricity by renewable sources by 2020 (Department of Trade and Industry 2003). However, the variations of winds and sunshine along the coasts are not always well predicted and some aspects of the governing dynamics still need to be studied in more detail, as recent studies on the coast of California have demonstrated (Rogers et al. 1998). Better prediction of flooding in high winds depends critically on more accurate calculation of coastal winds (Hunt 2005). The increased surface roughness over the land compared to that over the sea alters the direction, reduces the strength, and increases the turbulence of the wind (e.g. Caton 1977). In the UK, the 'sea-breeze' flows up to $30-150 \mathrm{~km}$ inland from the coastline on fine days (e.g. Simpson 1994). However, (as Manley (1955) implies in his classic book on British weather) these well-known effects do not explain some of the important features of coastal meteorology along the UK's coasts, namely the formation of low-level wind jets and the associated variation of cloudiness.

When considering local 'mesocale' weather, it is essential to consider the Earth's background rotation, i.e. the inertial Coriolis force, and also stable stratification, i.e. the restoring force due to buoyancy on a parcel of air displaced vertically (e.g. Rotunno et al. 1992). The Coriolis force is proportional to the wind speed $U(z)$ and the Coriolis parameter $f=2 \Omega \sin \phi$ (where $\phi$ is the latitude and $\Omega$ is the Earth's rate of rotation) and acts perpendicular to the wind direction. The coastal marine boundary layer is frequently stably stratified (Bergström and Barthelmie 2002) and capped by a temperature inversion at height $h_{0}$, i.e. a cool, moist, shallow marine layer moves under a less dense, warmer upper layer. Under these conditions the seabreeze forms if a surface temperature difference exists between the warm land and cool sea during daytime. This causes a pressure difference with the air accelerating from sea to land in response. The sea-breeze strengthens during the day and increasingly turns to the right in the northern hemisphere (i.e. veers) due to the Coriolis force, so that by the end of the day it tends to blow along the coastline rather than across it (e.g. Sutcliffe 1937; Simpson 1994) (see Fig. 1(a)). By contrast, neutrally-stratified, strong, synoptically-driven onshore winds are in geostrophic balance. The increased drag over land slows these winds, reducing the Coriolis force and deflecting them to the left in the northern hemisphere (i.e. 'backing'). This turning of the wind occurs downwind of the coastline, i.e. inland, and over a length scale of about $30 \mathrm{~km}$ in mid-latitudes (or of order $U_{10} / f$, where $U_{10}$ is the $10 \mathrm{~m}$ wind speed (e.g. Taylor 1977)) (see Fig. 1(b)).

However, these sharp changes across the coasts caused by discontinuities in both surface roughness and orography, cause significant inertial forces which are moderated by the effects of stable stratification (i.e. buoyancy force) and Coriolis force. These affect the airflow upwind as well as downwind of the coast, leading to local wind speed maxima and much higher gradients of wind speed, i.e. coastal jets (e.g. Ólafsson and Shapiro 2002, Capon 2003, Hunt et al. 2004). These jets extend from the edge of the roughness/orography change over a distance about equal to the Rossby deformation radius $L_{R}\left(=N h_{0} / f\right)$. (This is the

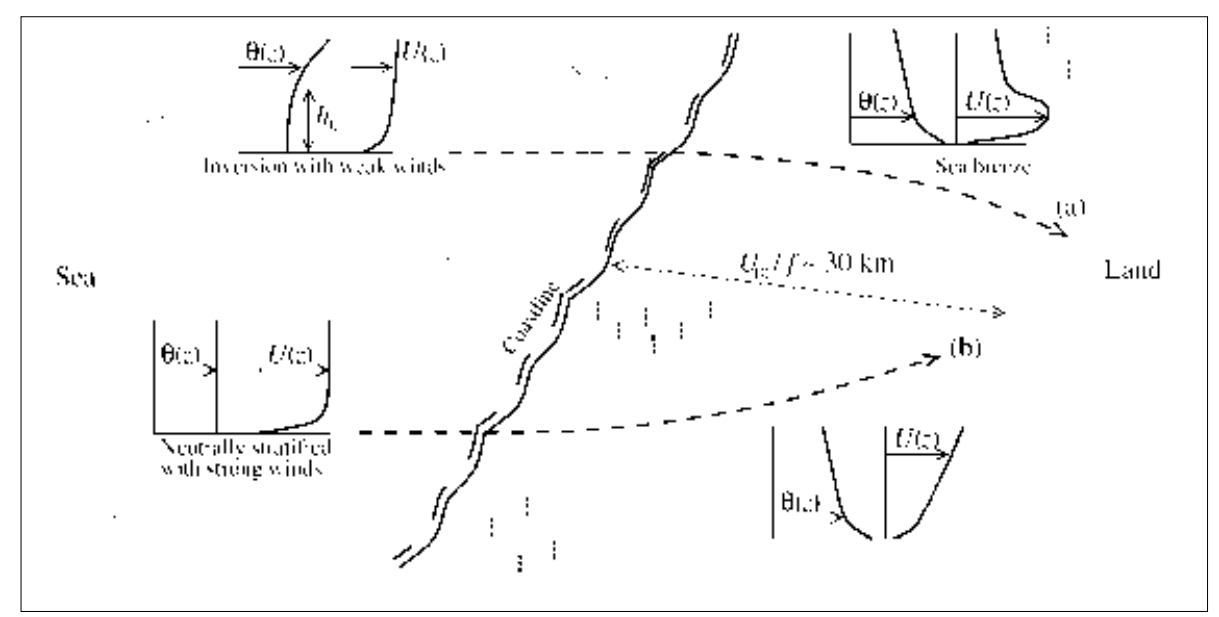

Fig. 1 Schematic diagram of the effect of Coriolis force on onshore winds in the northern hemisphere. $\theta(z)$ and $U(z)$ are the potential temperature and velocity profiles respectively. The surface of the land is warmer than that of the sea. In (a) a temperature inversion with weak winds forms a (weak) sea-breeze which turns to the right inland. In (b) neutrally stratified, strong winds turn to the left inland. $z$ is the vertical direction. 
characteristic horizontal extent for flows which are affected by both rotation and stable stratification, and is typically $30-300 \mathrm{~km}$ in mid-latitudes.) Here, $N=\sqrt{\left(g / \theta_{0}\right)(\partial \theta / \partial z)}$ is the Brunt Väisälä frequency, which characterises the stability of the atmosphere (where $g$ is the acceleration due to gravity, $\partial \theta / \partial z$ is the gradient of potential temperature, and $\theta_{0}$ is the reference temperature at the ground). Across the inversion $N \sim \sqrt{g^{\prime} / h_{0}}$, where $g^{\prime}=g \delta \theta_{I} / \theta_{0}$ and $\delta \theta_{I}$ is the rise in potential temperature. (Note for typical oceanic flows $L_{R}$ is much smaller (e.g. Røed 1996).)

Dynamically, these coastal jets are driven by the horizontal convergence and divergence of streamlines (Houghton 1992). In the northern hemisphere, as onshore winds cross the coastline, they are slowed by the increased surface drag and turn to the left (looking downwind). If the coast is on the right/left of the wind, this results in horizontal convergence/divergence inland, as shown by Fig. 2 . Associated with this is the inversion height rising/falling in the inland direction by a distance $h$, due to conservation of mass (Hunt et al. 2004). $h$ can vary by an amount of $100 \mathrm{~m}$ or more. For air parcels moving with the inversion layer, the temperature falls/rises, encouraging condensation/evaporation and more/less cloud inland. Over the land the boundary layer is less stable which tends to further increase the surface drag.

These perturbed flows are in approximate geostrophic balance over the scale $L_{R^{\prime}}$ i.e. the Coriolis force induces a wind jet parallel to the coastline and perpendicular to the sloping inversion height. This is explained by the equation $\left|g^{\prime} \partial h / \partial n\right| \sim\left|-f \bar{u}_{S}\right|$ (from equation (7(f)) of Hunt et al. (2004)), where $s$ and $n$ are the directions parallel and perpendicular to the coastline respectively. Here $\bar{u}_{S}$ denotes the average change in wind speed over the depth of the inversion layer, parallel to the coast. This is expressed as an amplification factor $\Delta$, so that $\bar{u}_{S}=\Delta \times \bar{U}$ where $\bar{U}$ is the average upwind velocity over the depth of the inversion layer. $\Delta$ varies logarithmically with the roughness length $z_{0}$ of the land surface and typically lies in the range $10-40 \%$ within a distance of order $L_{R}$ of the coast (Hunt et al. 2004). Note $\bar{U} \simeq U_{10}$.

If the onshore wind approaches the coast at an angle $\alpha$, then the peak wind of the coastal jet occurs at the coastline (see Fig. 3 ). The total average velocity parallel to the coast is expressed as the sum of the upwind velocity component $\bar{U}_{S}$ and the perturbation $\bar{u}_{S^{\prime}}$ i.e. $\bar{U}_{T_{S}}=\bar{U}_{S}+\bar{u}_{S}$ where $\bar{U}_{S}=\bar{U} \cos \alpha$. Note in the northern hemisphere for onshore winds, the inversion height is always higher on the right-hand side of the jet.

However, if the wind is parallel to a long straight coast, there is a sharp variation perpendicular to the coast, with the peak wind occurring about $1-2 \mathrm{~km}$ (of order $h_{0}$ ) off- shore from the coast (e.g. Ólafsson and Shapiro 2002, Capon 2003, Hunt et al. 2004). Downwind of a certain point $X$, the jet increases along the coast, reaching its maximum value at a distance $L_{R}$ downwind of $X$ (Hunt et al. 2004).

When the elevation of the ground increases by $H$ (e.g. at cliffs), the airflow rises and cools. The high pressure over the terrain produces jets whose directions are parallel to the coast in the anticyclonic direction with peak strengths of the order $\left(H / h_{0}\right) U_{10}$. (This contribution is generally smaller than that due to roughness change or the drag associated with hills (Capon 2003). It is not related to the direction of the wind in relation to the

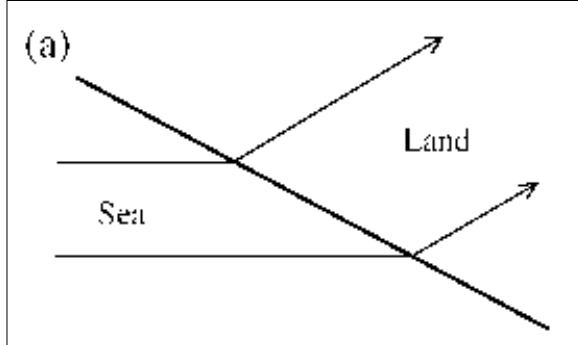

(b)

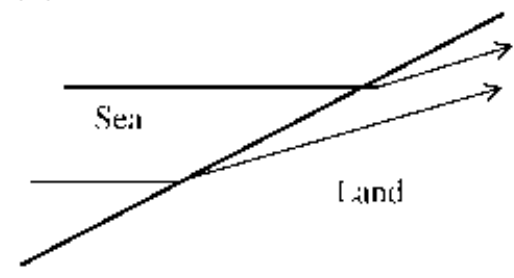

Fig. 2 Simplified diagram (i.e. without local effects) showing onshore streamlines in the northern hemisphere crossing the coastline and turning to the left. In (a) the coast is to the left of the wind (looking downwind) resulting in horizontal divergence of streamlines inland. In (b) the coast is to the right of the wind (looking downwind) resulting in horizontal convergence of streamlines inland.

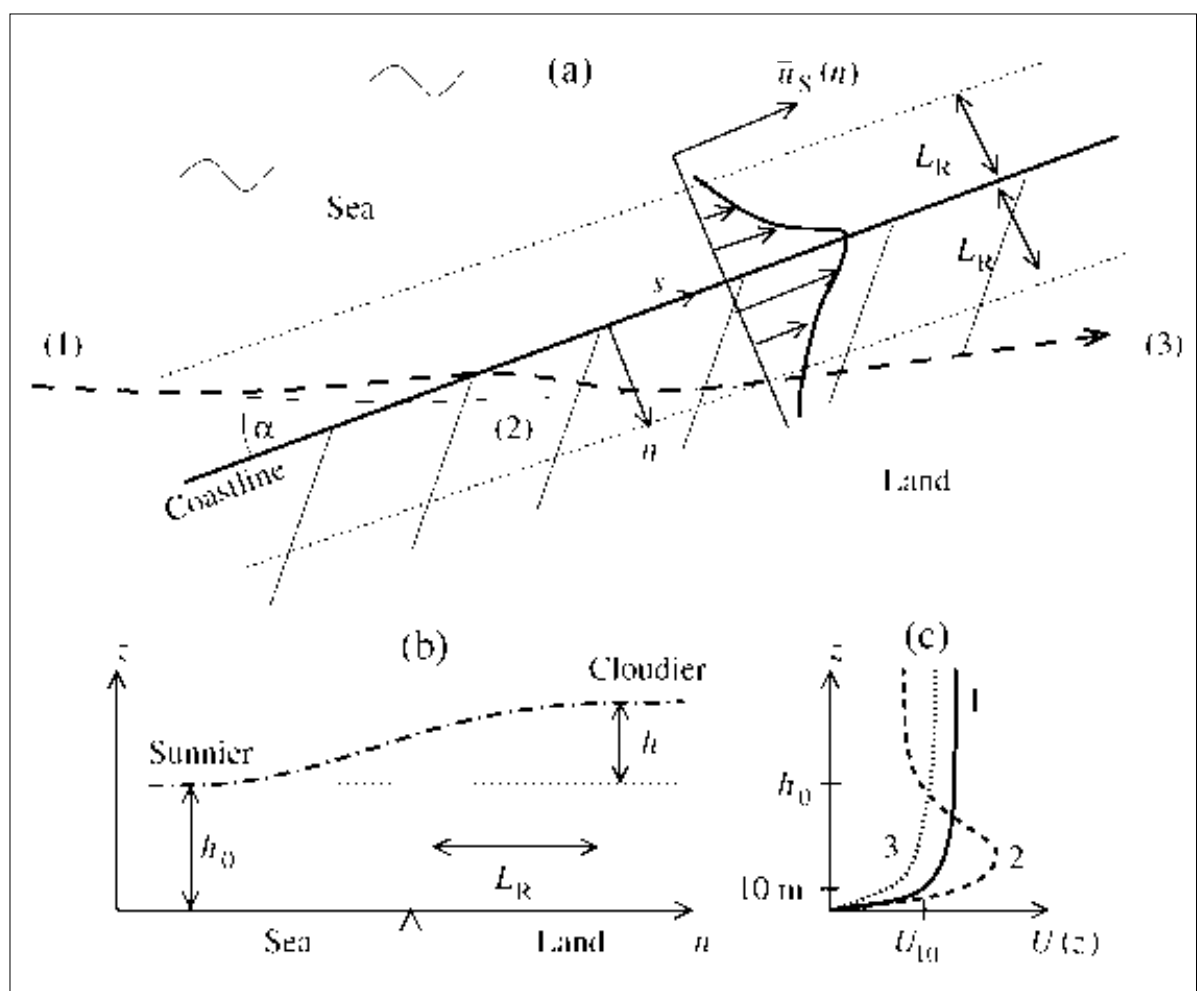

Fig. 3 Schematic diagram for the northern hemisphere showing onshore winds (from left to right) at an angle $\alpha$ to the coastline, where the coast is on the right of the wind looking downwind. In (a) the streamline (thick dashed line) turns to the left as it crosses the coastline, resulting in horizontal convergence of winds and a jet with average velocity perturbation $\bar{u}_{S}$ forming parallel to the coastline. In (b) associated increase of the inversion height inland, leading to it being cloudier inland. In (c) the velocity profile (upstream) over the sea (at position ' 1 '), over the coast (at position ' 2 '), and (downstream) over the land (at position ' 3 ') (here the wind slows due to the increased drag over land). Horizontal distances are of order $L_{R} \sim 50 \mathrm{~km}$ and vertical distances of order $h_{0} \sim 1-2 \mathrm{~km}$. Note the directions $s$ and $n$ are orientated in the flow direction, parallel and perpendicular to the coastline respectively. $z$ is the vertical direction. 
coastal wind jets and associated effects (Hunt et al. 2004).

Note that with offshore winds the same mechanism decreases the wind speed within a distance $L_{R}$ of the shore. Therefore, jets do not generally occur in these conditions (see Fig. 4).

Where the coast has a sharp angle, such as a 'cape' (e.g. off the northern French coast (around Cap Griz Nez near Boulogne)) or a 'junction' (e.g. the intersection of the North Wales and English coastlines), coastal jets either side of the angle can combine to form 'detached' jets with perturbation velocity $\bar{u}_{J}$ parallel to $\bar{U}$ (Hunt et al. 2004). Since they are associated with the increase/decrease in the inversion height, their dynamics are controlled by the Rossby radius $L_{R^{\prime}}$ and they lie along the streamline downwind of the sharp angle. The velocity is perturbed by a constant factor $\Delta$ (i.e. $\bar{u}_{J}=\Delta \times \bar{U}$ ). The jet may be directed offshore, e.g. north-easterly winds in the former case (see Fig. 5(a) and Fig. 8), or onshore for north-westerly winds in the latter case, leading to high wind speeds in the 'Cheshire Gap' (see Fig. 5(b)). Similar high winds occur downwind of the north-east corner of Lake Ontario in westerly winds and the southern tip of Greenland in winds with a westerly or easterly component (Orr et al.
2005). On the lee side of islands or headlands, the same mechanism produces wakes (or'negative' jets) of width $L_{R}$. These jets and wakes extend downwind over the sea for more than $100 \mathrm{~km}$ (i.e. greater than $L_{R}$ ), as satellite images (Freilich et al. 2004) over South Georgia Island and mesoscale modelling (Bergström and Barthelmie 2002) of the Baltic have demonstrated.

These Frictional-Coriolis-Buoyancy (FCB) coastal jets below the inversion layer are driven by horizontal inhomogeneity of the surface drag, and by the change in surface elevation. They are dynamically quite distinct from low-level, thermal-boundary layer (TBL) jets driven by variations in the surface heat flux with time or spatially in the wind direction (Owinoh et al. 2004). Examples of the latter are the well-known nocturnal jet (e.g. Blackadar 1957, Thorpe and Guymer 1977), or wind jets over the cold sea when wind comes off the warm land, such as over the Baltic (Smedman et al. 1995). The magnitude and direction of these TBL jets (first noted by Richardson (1923), using Dines' gun method of wind measurement), are affected by Coriolis forces over a time period $1 / f$ ( 3 hours) or distance $U_{10} / f(\sim 30 \mathrm{~km})$. But these TBL jets can exist without any significant effects of Coriolis forces, e.g. turning of

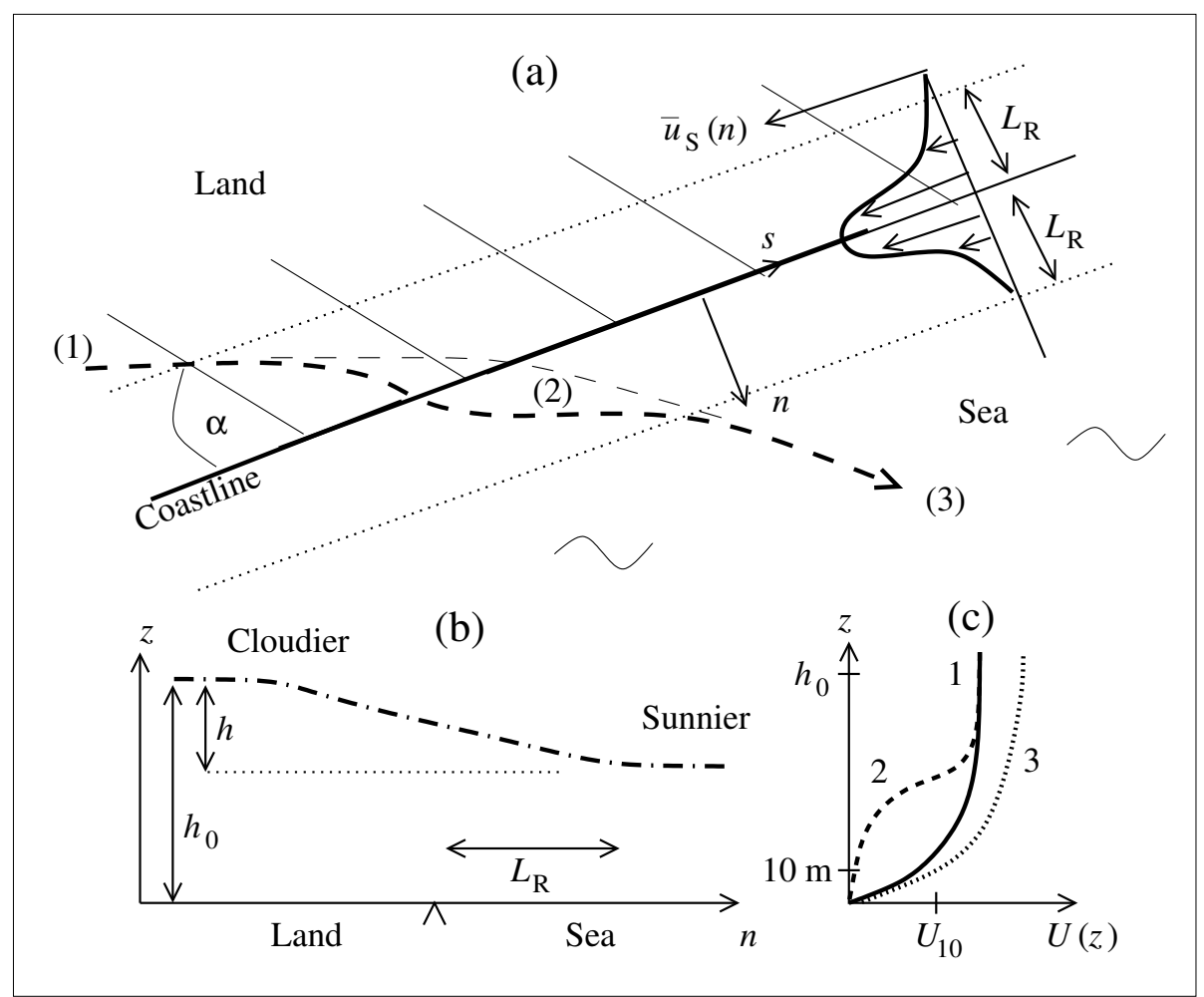

Fig. 4 Schematic diagram for the northern hemisphere showing offshore winds (from left to right) at an angle $\alpha$ to the coastline, where the coast is on the right of the wind looking downwind. In (a) the streamline (thick dashed line) turns to the right as it crosses the coastline, resulting in horizontal divergence of winds and a negative jet with average velocity perturbation $\bar{u}_{S}$ forming parallel to the coastline, reducing the overall wind speed downwind. In (b) associated decrease of the inversion height, leading to it being sunnier over the sea. In (c) the velocity profile (upstream) over the land (at position ' 1 '), over the coast (at position ' 2 '), and (downstream) over the sea (at position ' 3 ') (here the wind speeds up due to the decreased drag over sea). Horizontal distances are of order $L_{R} \sim 50 \mathrm{~km}$ and vertical distances of order $h_{0} \sim 1-2 \mathrm{~km}$. Note the directions $s$ and $n$ are orientated in the wind direction, parallel and perpendicular to the coastline respectively. $z$ is the vertical direction. the wind with height (Bonner 1968). Computations, theory and recent laboratory experiment (Owinoh et al. 2004) show that the basic driving force is a change in the turbulent shear stress caused by changes in stability (or Richardson number Ri associated with changing surface heat flux). (Note Ri is the square of the ratio of buoyancy frequency to the wind shear $(d U / d z)$.) The vertical profiles in these TBL jets have been observed at several sites, and can greatly increase the energy available from the mean wind. They also have the surprising effect of suppressing low-frequency vertical and horizontal fluctuations, which reduces the atmosphere-ocean heat flux, with consequences for the climate over high-latitude oceans (Smedman et al. 2004).

If the coastal orography is higher than the stable marine boundary layer, then the orography can act as a barrier (e.g. Shutts 1998) and modify the position and intensity of the TBL jet. This occurs along the Californian coast where the combination of strong coastal baroclinicity and the $400 \mathrm{~m}$ coastal topography frequently forms a strong, diurnal northerly low-level jet (e.g. Overland 1984, Zemba and Friehe 1987, Burk and Thompson 1996, Doyle 1997).

Note that both kinds of wind jets are welldocumented for coastal areas in north-west Europe (Bergström and Barthelmie 2002).

\section{Laboratory investigation of FCB jets}

The phenomenon of FCB jets when the wind is parallel to a coast, was studied experimentally using a rotating circular tank $(13 \mathrm{~m}$ in diameter and fluid depth $d=60 \mathrm{~cm}$ ) on the Coriolis turntable, Grenoble, France. This has been used previously for other studies of Coriolis effects on flow over mountains. A coastline (or area of roughness change) was simulated by a wide roughness strip of length (perpendicular to the flow) $B=100 \mathrm{~cm}$ and width (parallel to the flow) $D=200 \mathrm{~cm}$ (see Fig. 6(a)). This was placed on the tank floor and orientated so that the 'edge-line' of the strip was parallel to the flow. It comprised a staggered pattern of roughness elements (or blocks) of height $H=2 \mathrm{~cm}$ with a horizontal spacing of $6 \mathrm{~cm}$. The strip is curved so as to follow the curvature of the tank.

The tank fluid is stably/uniformly stratified with a density change $\delta \rho / \rho_{0}=0.02$ (where $\rho_{0}$ is a reference density), giving $N=\sqrt{(g / d)\left(\delta \rho / \rho_{0}\right)} \approx 0.6 \mathrm{~s}^{-1}$. This is much greater than the rotation rate of $\Omega=0.043 \mathrm{~s}^{-1}$. Mixing by the roughness strip generated an inversion layer near the ground at a local height $h_{0}$ of around $8.5 \mathrm{~cm}$. A flow (anti-clockwise) of about $1.0 \mathrm{~cm} \mathrm{~s}^{-1}$ was established by an impulsive reduction in rotation speed to $\Omega=0.038 \mathrm{~s}^{-1}$ (with $f=2 \Omega=0.076 \mathrm{~s}^{-1}$ ) (Boyer and Davies 2000). 


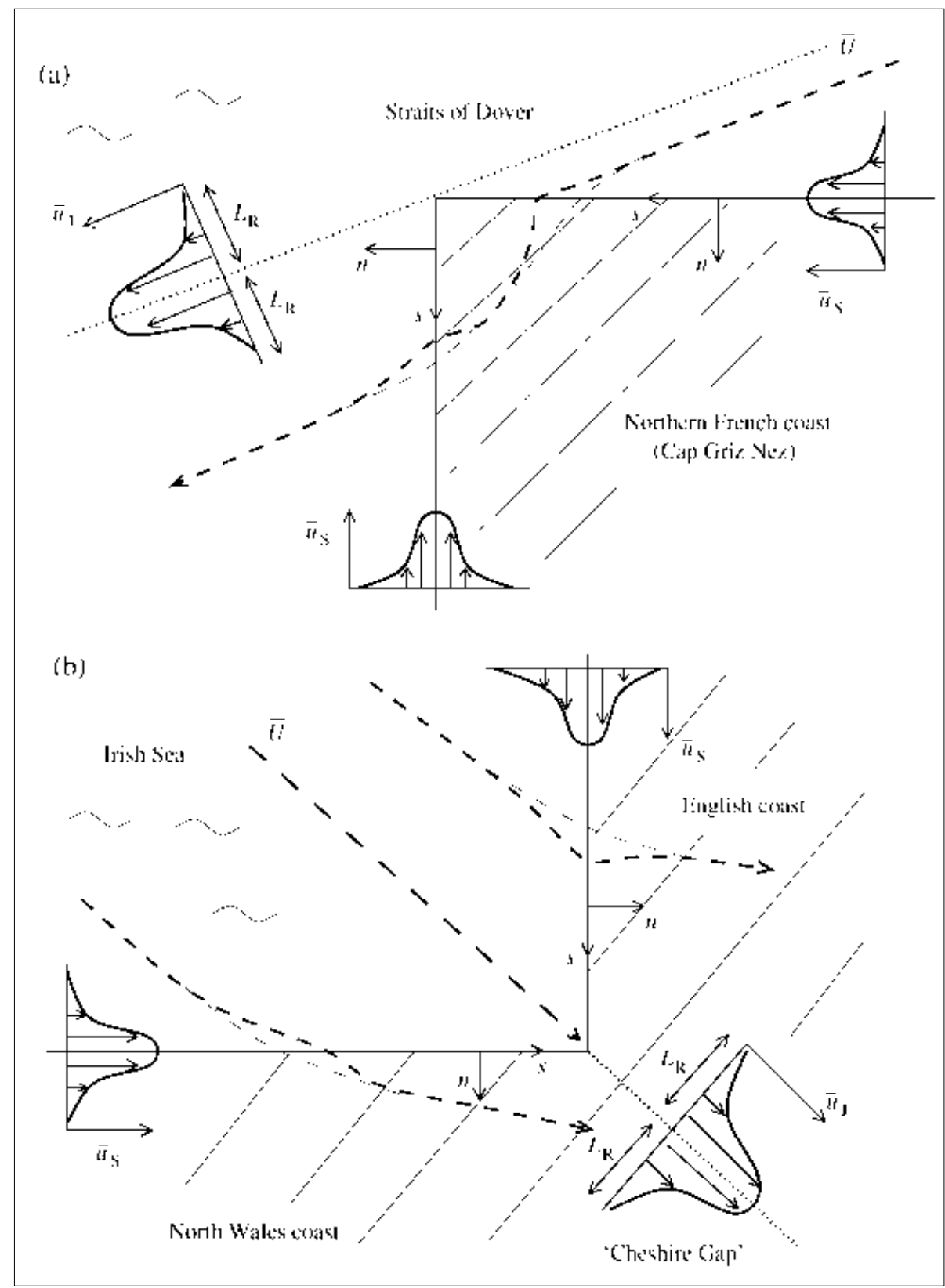

Fig. 5 Schematic diagram showing examples of detached jets Here coastal jets form on both coasts. These feed into a detached jet of width $L_{R}$ which lies parallel to the wind with velocity perturbation $\bar{u}_{J}=\Delta \times \bar{U}$. In (a) north-easterly winds produce positive onshore and negative offshore coastal jets along the coast of northern France near Cap Gris Nez which combine to produce a detached jet downwind. In (b) north-westerly winds produce positive coastal jets along both the North Wales and English coastlines which combine to produce high wind speeds in the 'Cheshire Gap.'

Here the Froude number $F=U /\left(N h_{0}\right) \approx 0.2$ (whose values determines the ratio of inertial to buoyancy forces, and defines the nature of flow over mountains and the behaviour of inversion layers) and $L_{R} \approx 0.5 N h_{0} / f \approx 30 \mathrm{~cm}$.

The flow was seeded with polystyrene particles of variable density illuminated by a horizontally orientated laser sheet. Bursts of four images were taken at different vertical levels, repeated five times for each observation. Pairs of images from each burst were analysed using Correlation Imaging Velocimetry to give the velocity fields (Fincham and Delerce 2000). The uncertainty of the measurement of their magnitude is estimated to be less than $\pm 3 \%$. (The five

velocity fields for each observation were averaged to give a single result.) Note that the spatial measurement error is not larger than $\pm 1 \mathrm{~cm}$.

Figure 6(b)(i) shows the velocity perturbation $u_{S}$ (in $\mathrm{cm} \mathrm{s}^{-1}$ ) parallel to the edge-line of the roughness strip at a vertical height $z=6.5 \mathrm{~cm}$ (i.e. $4.5 \mathrm{~cm}$ above the roughness blocks). (Fig. 6(b)(ii) shows the corresponding upwind velocity component $U_{S}$ at $z=6.5 \mathrm{~cm}$ (measured around $60 \mathrm{~cm}$ upwind). Note that it shows the expected radial shear due to the flow's azimuthal nature. The upwind velocity is slightly influenced by the roughness strip, contributing a slight overestimate of the calculation of $u_{S}$.) The figure shows that in the adjustment zone downwind of the leading edge of the roughness strip, at $s \approx 50 \mathrm{~cm}$, the peak velocity position is located around $20 \mathrm{~cm}$ to the left of the edge-line (looking downwind). Its magnitude is approximately $0.28 \mathrm{~cm} \mathrm{~s}^{-1}$, an amplification $\Delta$ of around $35 \%$ from the velocity upwind. Further downwind at $s \approx 100 \mathrm{~cm}$ following the initial adjustment of the flow, the peak perturbation occurs within a distance of order $h_{0}(\simeq 8.5 \mathrm{~cm})$ from the edge-line (with very large gradients in velocity across it). The magnitude is approximately $0.15 \mathrm{~cm} \mathrm{~s}^{-1}$, i.e. $\Delta \approx 20 \%$. At $s \approx 150 \mathrm{~cm}$ downwind, the peak perturbation has increased to approximately $0.25 \mathrm{~cm} \mathrm{~s}^{-1}$, i.e. $\Delta \approx 30 \%$. This still occurs close to the edge-line, within a distance of order $h_{0}$. Figure $6(\mathrm{c})$ (i) shows the horizontal profile of $u_{S}$ at around $s \approx 100 \mathrm{~cm}$ for different vertical levels. (Figure 6(c)(ii) shows the corresponding upwind velocity component $U_{S}$.) As the height $z$ increases, the jet becomes thicker and $u_{S}$ decreases (i.e. the maximum perturbation of the jet at $z \approx h_{0} \simeq 8.5 \mathrm{~cm}$ is half that at $z \approx 6.5 \mathrm{~cm}$ ).

As the flow impacts on the roughness strip perpendicular to the approach flow, a strong 'barrier' jet of thickness $L_{R}$ is formed over the upwind edge of the roughness strip (not shown). This leads to the deflection of the 'edge' jet to the left of the edge-line (looking downwind) for $s$ less than or similar to $L_{R}$. Here the jet is amplified by the combination of the barrier jet and edge jet. For $s>L_{R}$, the edge jet forms closer to the coast, leading to a lower value of $u_{S}$. The effect of the barrier jet has become negligible. Note how the edge jet increases downwind as $s$ increases from 100 to $150 \mathrm{~cm}$, as the theory predicts.

Note that there are transient effects in this experiment which will be described in more detail in a later paper.

\section{High-resolution numerical modelling for a meteorological case-study over the Dover Straits region of the English Channel}

The mean sea level pressure (MSLP) analysis for 0000 UTC 23 July 2000 (see Fig. 7(a)) shows an anticyclone centred to the north of Scotland, implying north-easterly geostrophic flow across the east coast of England and easterly geostrophic flow along its southern coast. Observations at 0900 UTC (see Fig. 7(b)) showed north-easterly low-level winds over Southern England and the English Channel (consistent with the increased surface drag over land turning the easterly geostrophic wind at surface level slightly to the left). Radiosonde ascents from Herstmonceux on the English south coast showed that a strong inversion persist- 
โi]
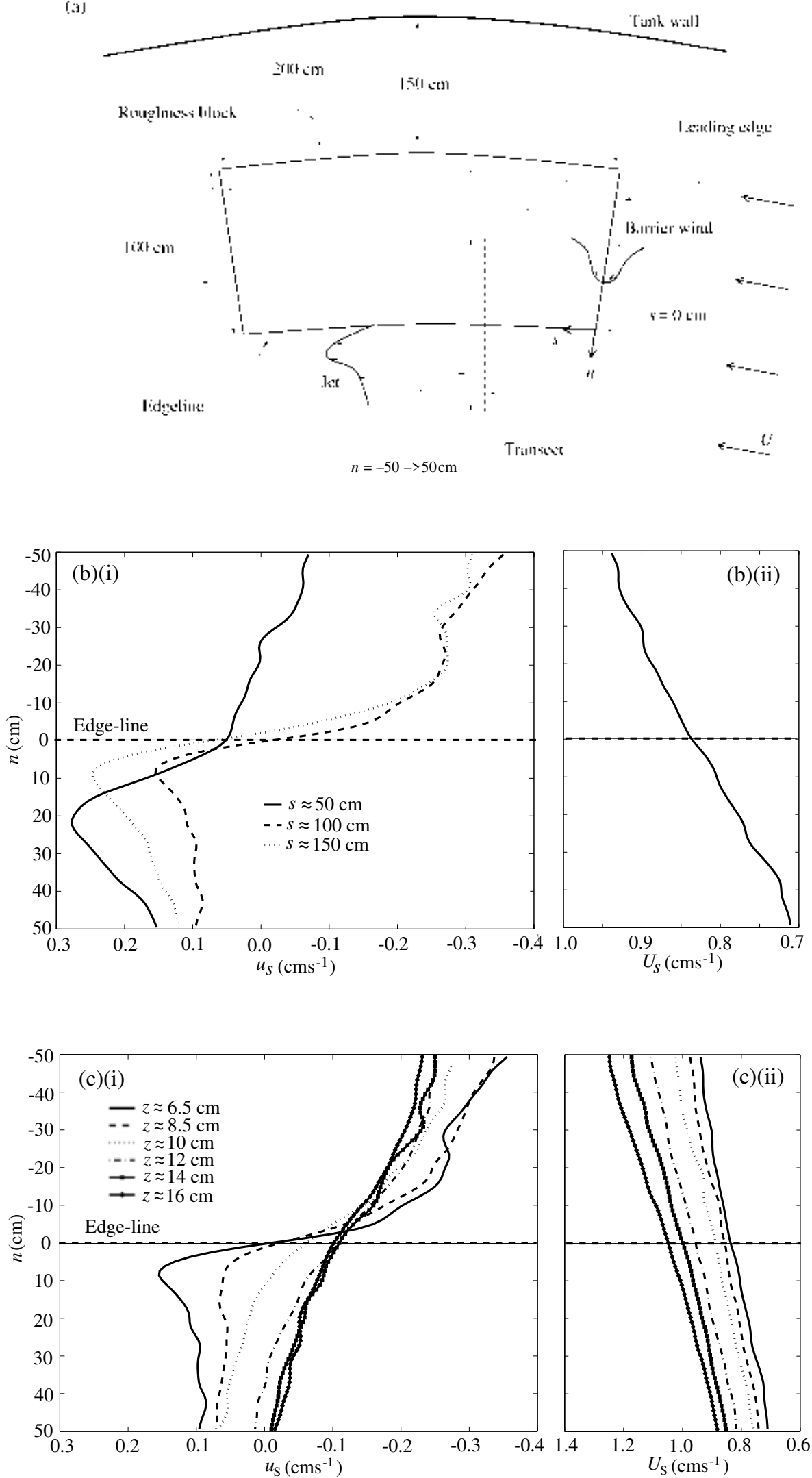

Fig. 6 Schematic drawing of the experimental setup (not drawn to scale). The coastline is simulated by a wide roughness strip, with its 'edge-line' orientated parallel to the flow. Note the directions $s$ and $n$ are orientated parallel and perpendicular to the edge-line of the roughness strip respectively. $s=0$ is defined at the upper edge of the roughness strip and $n<0$ is over the roughness strip. $z$ is the vertical direction. The velocity field is measured across $100 \mathrm{~cm}$ transects, centred on the edge-line of the roughness strip and at multiple vertical levels. (b) (i) Variation of the velocity perturbation $u_{S}$ at $z=6.5 \mathrm{~cm}$ along the edge-line of the roughness strip. (b) (ii) Upstream velocity component $U_{S}$ at $z=6.5 \mathrm{~cm}$. (c) (i) Horizontal profile of $u_{S}$ at $s=100 \mathrm{~cm}$ for different vertical levels. (c)(ii) Horizontal profile of the upstream velocity component $U_{S}$ for different vertical levels. 

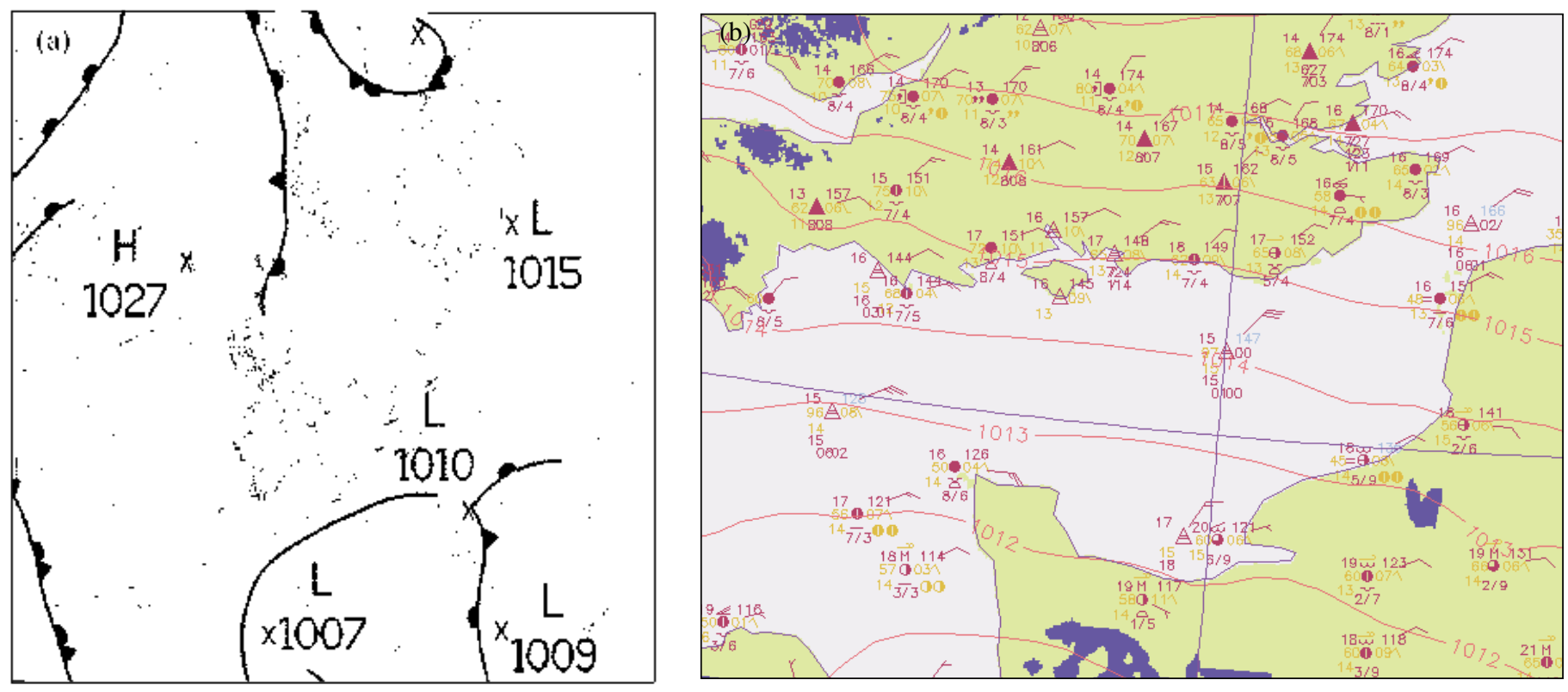

Fig. 7 (a) Synoptic analysis for 0000 UTC 23 July 2000 (b) Observations at 0900 UTC 23 July 2000. Greenwich Light Vessel is situated at $\left(50^{\circ} 25^{\prime} \mathrm{N}, 0^{\circ} \mathrm{E}\right)$

ed throughout the day at a height $h_{0}$ of around $800 \mathrm{~m}$ (with a temperature change $\delta T \approx 5 \mathrm{~K}$ at this height; see Capon 2003). Here $N=\sqrt{\left(g / h_{0}\right)\left(\delta T / T_{0}\right)} \sim 0.014 \mathrm{~s}^{-1}\left(T_{0}\right.$ is a reference temperature), giving $L_{R} \sim 90 \mathrm{~km}$ (taking $\left.f \sim 1.2 \times 10^{-4} \mathrm{~s}^{-1}\right)$.

Figure 8 shows the 1100 UTC simulation of the $10 \mathrm{~m}$ wind over the Dover Straits region of the English Channel, forecast from 0000 GMT using the Met Office's 'New Dynamics' Unified Model with a horizontal grid resolution of $2 \mathrm{~km}$. (The New Dynamics Model has been used operationally within the Met Office since August 2002. It utilises the full mathematical equation set for the dynamics of the atmosphere (Davies et al. 2004).) The entrance to the Dover Straits is around $30 \mathrm{~km}$ wide (from here it extends around $300 \mathrm{~km}$ westwards). Upwind of this region the simulation shows the $10 \mathrm{~m}$ wind speed is around $8 \mathrm{~m} \mathrm{~s}^{-1}$, giving a Froude number $F \simeq 0.7$. By the time this flow has reached the entrance to the Dover Straits, the predicted velocity has increased to around $10 \mathrm{~m} \mathrm{~s}^{-1}$. This is in agreement with the observations at 0900 UTC (see Fig. 7(b)) which also show here a $10 \mathrm{~m}$ wind speed of around $10 \mathrm{~m} \mathrm{~s}^{-1}$ (or $20 \mathrm{kn}$ ).

Computations show that, downwind of the entrance, sharp gradients in velocity form along the English coastline (at ' $a$ '), with $10 \mathrm{~m}$ winds strengthening to their peak value on the seaward side within three $\mathrm{km}$ of the coast. They weaken on the landward side. This is consistent with the north-easterly winds approaching approximately parallel to the coast and producing a coastal jet hugging the south coast of England.

Along the streamline ( $a t^{\prime} b$ '), downwind of Cap Gris Nez, northern France, there are sharp gradients in velocity normal to the wind. The peak $10 \mathrm{~m}$ wind speed is about
$11 \mathrm{~m} \mathrm{~s}^{-1}$. This is consistent with the formation of a detached jet.

In the centre of the channel (shown as ' $\mathrm{C}$ ') there is a large speed-up region starting at the entrance to the Dover Straits and extending westwards past the Isle of Wight. Predicted $10 \mathrm{~m}$ wind speeds increase along the centre of the channel and reach a maximum in excess of $12 \mathrm{~m} \mathrm{~s}^{-1}$, i.e. $\Delta \approx 50 \%$. Observations at Greenwich Light Vessel (see Fig. 7(b)) demonstrated this speed-up, but the super-geostrophic winds as measured for much of the day exceeded the simulated winds with hourly speeds of up to $15 \mathrm{~m} \mathrm{~s}^{-1}$

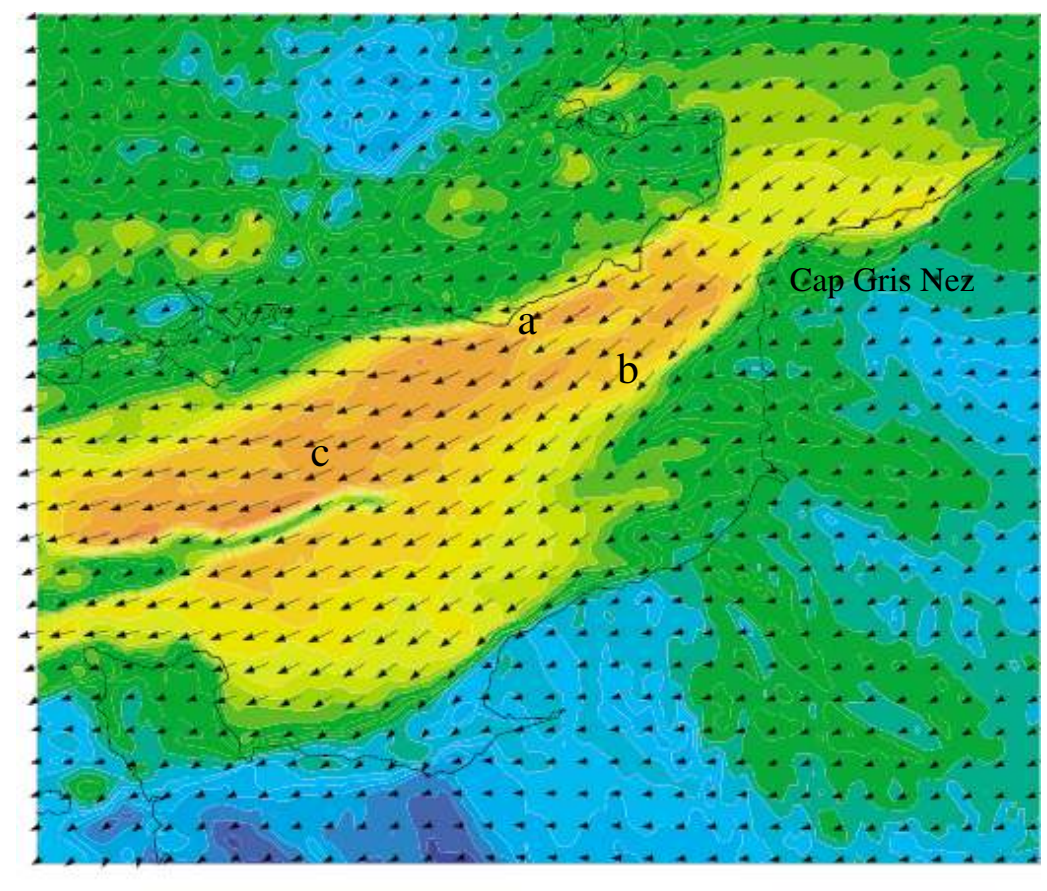

- 10

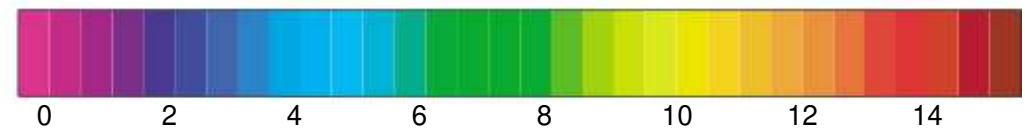

Fig. $810 \mathrm{~m}$ wind speed $\left(\mathrm{m} \mathrm{s}^{-1}\right)$ at 1100 UTC on 23 July 2000 over the Dover Straits region of the English Channel, computed using the Met Office New Dynamics Unified Model with a horizontal resolution of $2 \mathrm{~km}$. Wind arrows from every 5 th model point are overlaid. 
(30 kn). The overall wind profile across the channel is consistent with it being formed by two main elements, namely the coastal jet in the northern side and a detached jet from Cap Griz Nez. When the wind backs and is not exactly parallel to the Kent coast, the coastal wind jet on the northern side is transformed into a detached jet which forms along the streamline passing the tip of Kent (see Hunt et al. 2004).

Examination of the vertical structure of the jet showed that the maximum wind was at a height of about $200 \mathrm{~m}$ and about 16-17 $\mathrm{m} \mathrm{s}^{-1}$ (not shown).

Since the width of these jets is of order $L_{R} \sim 90 \mathrm{~km}$, they overlap each other and produce a relatively constant velocity in the centre of the channel. Note that the coastal jet on the northern side causes the speed to increase with distance downwind from the entrance to the Dover Straits, reaching its maximum where the coastline changes at Beachy Head (at 'a'). A similar analysis in terms of coastal wind jets for other wind directions also appears to be consistent with observed winds across the channel.

\section{Associated variation in cloudiness and precipitation}

The preceding analysis predicts that for this meteorological case-study, the inversion layer height would be greatest on the righthand side of the coastal jet which forms between Dover and Beachy Head. This is verified by the numerical simulation which showed the inversion height highest inland over the English coastal region at $600-800 \mathrm{~m}$, and sloping downwards to 200-400 m over the English Channel. This is further confirmed by Advanced Very High Resolution Radiometer channel 1 (visible) satellite data at 1423 GMT of this day (see Fig. 9), showing a large amount of cloud over south-east England and the North Sea which thins over the Dover Straits region and then disappears, consistent with the inversion height falling over the sea. Over central southern England, surface divergence (see Fig. 8) and perhaps surface heating during the day, have possibly led to the cloud clearing. The sky over the English southern coast is predominately clear, despite surface convergence in this region (see Fig. 8), indicating that the air over this region may be comparatively dry after having travelled over land for some time. Seabreeze and orographic effects may also be significant in this region.

Frequently, the winds in the English Channel are south-westerly. As these winds approach the Dutch coast (i.e. with the coast on the right) horizontal convergence of streamlines can result in the inversion height increasing inland where it is often cloudier than on the coast (c.f. Fig. 2(b) and Fig. 3). This provides a meteorological reason for the Dutch bulb fields being so close to the coast (F. Nieuwstadt, private communication). By contrast, on the southern coast of England with these winds, the coast is on the left of the wind (c.f. Fig 2(a)). Here, horizontal divergence of the streamlines can result in the inversion height decreasing inland where it is often sunnier than on the coast, aided by the lee effect of the South Downs.

A meteorological case-study for these conditions is on 25 January 2001. The MSLP analysis for 0000 UTC (see Fig. 10(a)) shows a low-pressure system anchored west of UK, creating a strong, well-defined west-southwesterly flow. This entered the English Channel at a speed of approximately $12 \mathrm{~m} \mathrm{~s}^{-1}$. Radiosonde data at around 2300 UTC 24 January 2001 over the English south coast showed that an inversion existed at a height of around $2000 \mathrm{~m}$ (with a temperature change $\delta T \approx 7 \mathrm{~K}$ at this height). There was quite moist air near the surface and much drier air at 3-4 km height. Later in the day at around 1100 UTC, the inversion had disappeared and the air was drier. Fig. 10(b) shows a composite of Moderate Resolution Imaging Spectroradiometer channel 1, 3 and 4 (all visible) satellite data at around 1200 UTC. A large amount of cloud is evident over the English Channel which abruptly disappears inland over southern England. Clear skies are evident over the Dover Straits region of the Channel, with cloud abruptly beginning inland of the Dutch and Belgium coastlines. (Note that if the clouds were determined by a sea-breeze front along the Dutch and Belgium coastlines, clear sky would be apparent over much of the coastal fringes with cloud development beginning significantly inland (Damato et al. 2003).)

Similar dynamics causes the asymmetry of the inversion height and the according sunshine and precipitation variation as airflow approaches mountains (Hunt et al. 2001). An excellent example is provided by $\mathrm{New}$ Zealand which is aligned north-south and has a mountain chain extending the length of its country. Here the typical westerly winds produce a sunnier climate (and excellent wine) at the northern end of its South Island, and high precipitation at the southern end (Brenstrum 1998). Table 1 shows the annual values of sunshine duration and precipitation for the period 1971-2000 for the New Zealand stations of Blenheim, Invercargill Airport, and Wellington. The mean annual sunshine at Blenheim located at the extreme north of New Zealand's South Island is almost 50\% greater, and the mean annual precipitation around $40 \%$ less, than at Invercargill Airport located at the extreme south of South Island. Note this is partly due to the southern region being exposed to much more showery southwesterly winds (Brenstrum 1998). Moreover, the precipitation at Wellington located at the extreme south of North Island is almost double that at Blenheim (although Blenheim is partially sheltered by the massive Southern Alps which lie to its west and south, Wellington is located just the other side of Cook Strait!). Similar effects are seen over the large plateau of Southern Greenland (Orr et al. 2005).

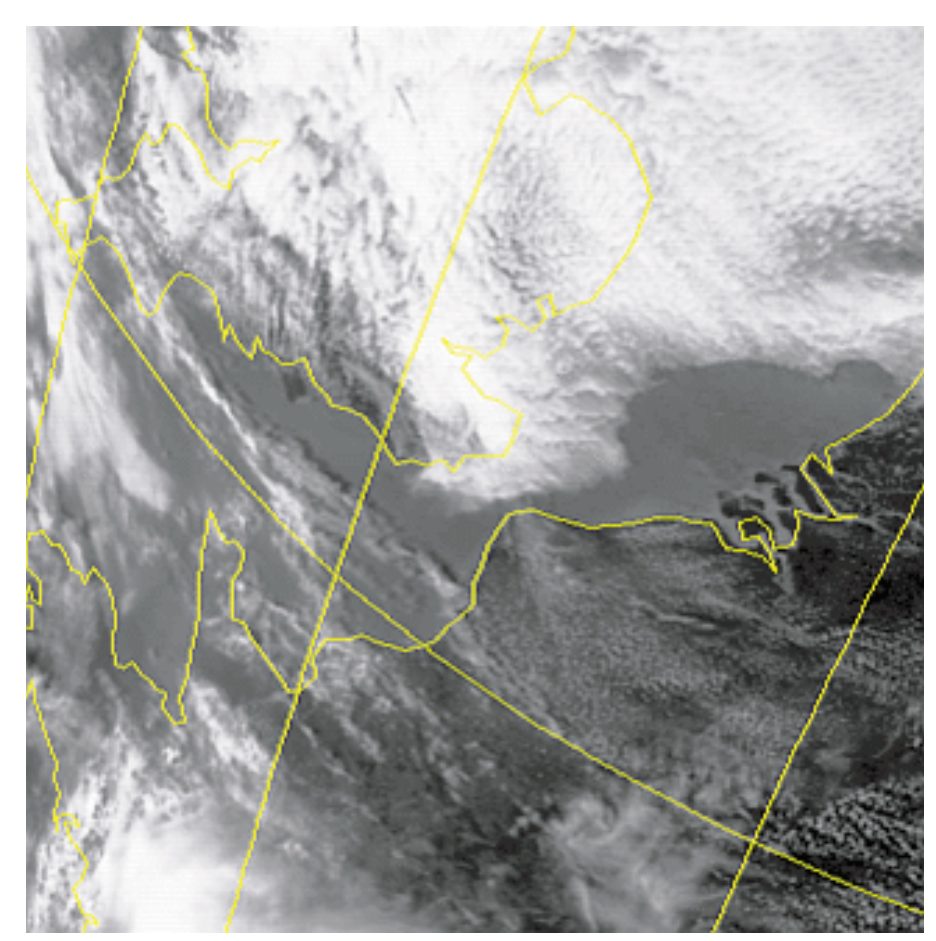

Fig. 9 Visible satellite image at 1423 UTC 23 July 2000 

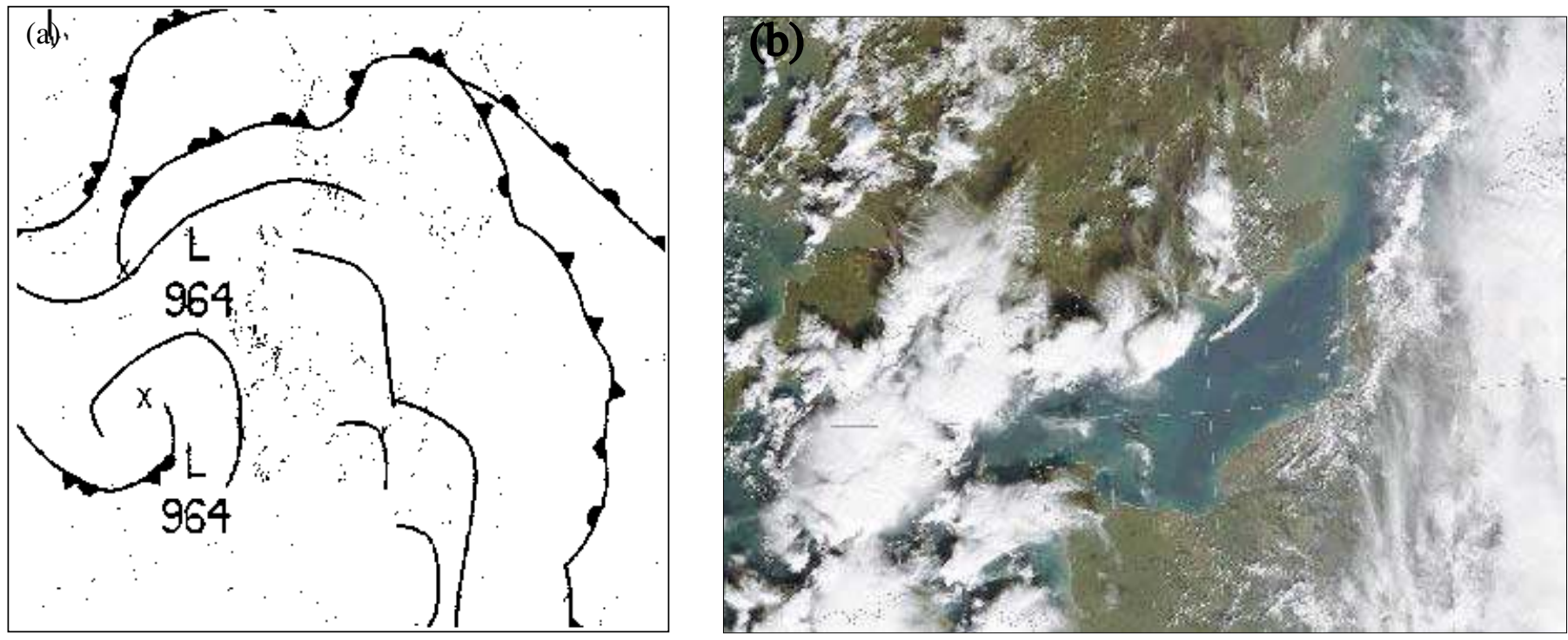

Fig. 10 (a) Synoptic analysis for 0000 UTC 25 January 2001. (b) Visible satellite image at around 1200 UTC 25 January 2001

Table 1

Annual values of sunshine duration and precipitation for the 1971-2000 period for selected stations in New Zealand's South and North Islands

\begin{tabular}{llll}
\hline Station & Region & Sunshine (hr) & Precip. (mm) \\
\hline Blenheim & Extreme north of S. Island & 2409 & 655 \\
Invercargill Airport & Extreme south of S. Island & 1614 & 1112 \\
Wellington & Extreme south of N. Island & 2065 & 1249
\end{tabular}

\section{Discussion}

Theory, laboratory experiment, and numerical mesoscale simulations show how wind jets driven by Frictional-Coriolis-Buoyancy (FCB) forces are likely to be widespread around coasts when the wind is at an angle or parallel to the coast, especially when the lower troposphere is stably stratified or there is a strong inversion layer. The Froude number $F$ of this layer is small. The FCB jets are typically a few hundred metres deep, occurring within the boundary layer. Their peak velocity can be up to $40 \%$ greater than the upstream speed. The jets extend a distance of the order of the Rossby deformation radius $L_{R}$ from the coastline. With onshore winds at an acute angle, the peak wind is approximately located along the coast. Note that the directions of the perturbed coastal jets are not necessarily the same when they are caused by roughness change and by elevation change.

If the wind is parallel to a straight coast, the wind speeds reach a maximum offshore at around $1-2 \mathrm{~km}$ (or of the order of the inversion height $h_{0}$ ) from the coast, and decrease equally rapidly inland. Also in this case, the peak wind perturbation tends to increase downwind. Where the wind approaches perpendicular to a peninsula (e.g. Kent in Fig. 8) or mountain range (e.g.
Alps, Pyrenees) where significant roughness and elevation changes occur, a barrier jet of width around $50 \mathrm{~km}\left(\sim L_{R}\right)$ is formed upwind. This affects the flow downwind where the coastline or contours change their direction. In general, wherever such changes in direction occur, detached jets form parallel to the wind direction. This has a significant effect on the peak wind speeds.

The jets are regions of intense surface turbulence caused by the higher wind speeds. These winds are associated with variations in the height of the inversion layer of the order of $100 \mathrm{~m}$ or more that are sufficient to produce strong variations of cloudiness, fog, and precipitation with distance from the coast, depending on the orientation of the wind. Note that mechanisms such as the sea-breeze, sea-land transitions, orographic effects, or 'burn-off' due to absorption of solar radiation in the cloud layer cannot solely be responsible for the observed increasing/decreasing cloudiness inland (in the northern hemisphere) when the coast is on the right/left as the airflow approaches from the sea.

These effects can be quite simply understood in terms of low-level convergence and divergence of winds under influence of Coriolis forces. They are not driven by changing surface heating. However, they are not adequately covered in current text book and forecasters handbooks. Numerical codes can only capture them using very fine scale meshes of the order of two km resolution. As well as variations in cloudiness, they are associated with increased wind stress, storm surge, ocean up/downwelling, sea-ice movement, etc. Hence a practical application of this study is to improve their parameterisation. Approximate models for personal computers are being developed to provide local forecasting of wind energy, based on linearised models (e.g. Flowstar, 3dvOM).

\section{Acknowledgments}

We are grateful to the two anonymous reviewers, whose detailed comments greatly improved the paper. We would like to thank P. Clark, P. Davies, E. Fouhy, B. Golding, E. Hanna, C. Sherrard and A. Wilchinsky for useful discussions on this topic. The laboratory work was supported by the EEC contract 'Transnational Access to Major Research Infrastructures' HPRI CT 200100168, with much technical support from S. Decamp, H. Didelle, S. Mercier, E. ThivolleCazat, and S. Viboud. Thanks to the British Atmospheric Data Centre for providing access to the Met Office's surface and radiosonde data and to the National Institute of Water and Atmospheric Research for providing access to the surface observation data over New Zealand. The MSLP analysis charts used are copyright of the Met Office. We are grateful to the University of Dundee Satellite Receiving Station and NOAA for supplying the satellite images. This work was supported by grants from Natural Environment Research Council to the Department of Space \& Climate Physics at University College London. 


\section{References}

Bergström, H. and Barthelmie, R. J. (2002) Offshore boundary-layer modelling. Proc. (CD-ROM) of the 2002 Global Windpower Conference, Paris, 2-5 April 2002

Blackadar, A. K. (1957) Boundary layer wind maxima and their significance for the growth of nocturnal inversions. Bull. Amer. Meteorol. Soc., 38, pp. 283-290

Bonner, W. D. (1968) Climatology of the low-level jet. Mon. Weather Rev., 96, pp. 833-850

Boyer, D. L. and Davies, P. A. (2000) Laboratory studies of orographic effects in rotating and stratified flows. Annu. Rev. Fluid Mech., 32, pp. 165-202

Brenstrum, E. (1998) The New Zealand weather book. Craig Potton Publishing, Nelson, New Zealand

Burk, S. D. and Thompson, W. T. (1996) The summertime low-level jet and marine boundary layer structure along the California coast. Mon. Wea. Rev., 124, pp. 668-686

Capon, R. (2003) Wind speed-up in the Dover Straits with the Met Office New Dynamics Model. Meteorol. Appl., 10, pp. 229-237

Caton, P. G. F. (1977) Standardised maps of hourly mean wind speeds over the United Kingdom and some implications regarding wind speed profiles. Proc. of the fourth international conference on Wind Effects on Buildings and Structures, Heathrow, 1975, Cambridge University Press, Cambridge, UK, pp. 7-21

Damato, F., Planchon, O. and Dubreuil, V. (2003) A remote-sensing study of the inland penetration of sea-breeze fronts from the English Channel. Weather, 58, pp. 219-226

Davies, T., Cullen, M. J. P., Malcolm, A. J., Mawson, M. H., Staniforth, A., White, A. A. and Wood, N. (2004) A new dynamical core for the Met Office's global and regional modelling of the atmosphere. Q. J. R. Meteorol. Soc., 131, pp. 1759-1782

Department of Trade and Industry, UK (2003) Energy White Paper: Our energy future - creating a low carbon economy, The Stationary Office, London

Doyle, J. D. (1997) The influence of mesoscale orography on a coastal jet and rainband. Mon. Weather Rev., 125, pp. $1465-1488$

Fincham, A., and Delerce, G. (2000) Advanced optimization of correlation imaging velocimetry algorithms. Experiments in Fluids, pp. S13-S20

Freilich, M. H., Vanhoff, B. A., Long, D. G. and Dunbar, R. S. (2004) A multi-satellite case study of winds and clouds near South Georgia Island. Mon. Wea. Rev., Submitted

Houghton, D. (1992) Wind Strategy. Fernhurst Books, Brighton, UK

Hunt, J. C. R., Ólafsson, H. and Bougeault, P. (2001) Coriolis effects on orographic and mesoscale flows. Q. J.R. Meteorol. Soc., 127, pp. 601-633
Hunt, J. C. R., Orr, A., Rottman, J. W. and Capon, R. (2004) Coriolis effects in mesoscale shallow layer with sharp changes in surface conditions. Q. J. $R$. Meteorol. Soc., 130, pp. 2703-2731 (Note corrigendum to be published)

Hunt, J. C. R. (2005) Inland and coastal flooding: developments in prediction and prevention. Phil. Trans. Royal Society, 363, pp. 1475-1491

Manley, G. (1955) Climate and the British scene. Collins New Naturalist Series, London

Ólafsson, H. and Shapiro, M. (2002)

Observations and numerical simulations of a wake and corner winds in a strong windstorm over Iceland. Proc. 10th Conf. Mountain Meteorology, Amer. Meteorol. Soc., Park City, UT, USA, 17-21 June, pp. 408-411

Orr, A., Hanna, E., Hunt, J. C. R., Cappelen, J., Steffen, K. and Stephens, A. (2005) Characteristics of stable flows over Southern Greenland. Special edition of Pure Appl. Geophys. on 'Weather and Climate', 162

Overland, J. E. (1984) Scale analysis of marine winds in straits and along mountainous coasts. Mon. Wea. Rev., 112, pp. 2532-2536

Owinoh, A. Z., Hunt, J. C. R., Orr, A., Clark, P., Klein, R., Fernando, H. J. S. and Nieuwstadt, F. T. N. (2004) Effects of changing surface heat flux on the atmospheric boundary layer flow over flat terrain. Boundary-Layer Meteorol., In press Richardson, L. F. (1923) Wind above the night-calm at Benson at 7 a.m. Q. J.R. Meteorol. Soc., 49, pp. 377

Røed, L. P. (1996) Modelling mesoscale features in the ocean. In Waves and Nonlinear Processes in Hydrodynamics, ed J. Grue, B. Gjevik, J. E. Weber, Dordrecht, The Netherlands, Kluwer Academic, pp. 383-96

Rogers, D. P., Dorman, C. E., Edwards, K. A., Brooks, I. M., Melville, W. K., Burk, S. D., Thompson, W. T., Holt, T., Ström, L. M., Tjernström, M., Grisogono, B., Bane, J. M., Nuss, W. A., Morley, B. M. and Schanot, A. J. (1998) Highlights of coastal waves 1996. Bulletin of the Amer. Meteorol. Soc., 79, pp. 1307-1326

Rotunno, R., Curry, J. A., Fairall, C. W. Friehe, C. A., Lyons, W. A., Overland, J. E., Pielke, R. A., Rogers, D. P., Stage, S. A., Geernaert, G. L., Nielsen, J. W. and Sprigg, W. A. (1992) Coastal meteorology - A review of the state of the science. Panel on Coastal Meteorology, Committee on Meteorological Analysis, Prediction, and Research, Board on Atmospheric Sciences and Climate, Commission on Geosciences, Environment, and Resources. National Research Council, National Academy Press, Washington, D.C., USA

Shutts, G. (1998) Idealised models of the pressure force on mesoscale mountain ridges. Contrib. Atmos. Phys., 71, pp 303-313

Simpson, J. E. (1994) Sea breeze and local wind. Cambridge University Press, Cambridge, UK, 234 pp.
Smedman, A. S., Bergström, H., and Högström, U. (1995) Spectra, variances and length scales in a marine boundary layer dominated by a low level jet. Boundary-Layer Meteorol., 76, pp. 211-232

Smedman, A. S., Högström, U. and Hunt, J. C. R. (2004) Effects of shear sheltering in a stable atmospheric boundary layer with strong shear. Q. J. R. Meteorol. Soc., 130, pp. 31-50

Sutcliffe, R. C. (1937) The sea breeze at Felixstowe. A statistical investigation of pilot balloon ascents up to 5,500 feet. Q. J. R. Meteorol. Soc., 63, pp. 137-146 Taylor, P. A. (1977) Some numerical studies of surface boundary layer flow above gentle topography. Boundary-Layer Meteorol., 11, pp.439-465

Thorpe, A. J. and Guymer, T. H. (1977) The nocturnal jet. Q. J. R. Meteorol. Soc., 103, pp. 633-653

Uotila, J. (2001) Observed and modelled sea-ice drift response to wind forcing in the northern Baltic Sea. Tellus, 53A, pp. 112-128

Zemba, J. and Friehe, C. A. (1987) The marine atmospheric boundary layer jet in the coastal ocean dynamics experiment. J. Geo. Res., 92, pp. 1489-1496 